\title{
Carotid endarterectomy: a comparison on general and local anesthesia
}

\author{
Faruk Toktas ${ }^{1}$, Tugrul Goncu', Suleyman Surer ${ }^{1}$, Gunduz Yumun ${ }^{1}$, Kadir Kaan Ozsin ${ }^{1}$, Burak Erdolu ${ }^{1}$, \\ Senol Yavuz ${ }^{1}$, Arif Gucu ${ }^{1}$ \\ ${ }^{1}$ Department of Cardiovascular Surgery, Bursa Yuksek Ihtisas Education and Research Hospital, Bursa, Turkey
}

\begin{abstract}
Objective. Carotid endarterectomy (CEA) reduces disabling or fatal stroke risk in patients with significant carotid stenosis. The aim of this study was to compare the results of CEA performed under general anesthesia (GA) or local anesthesia (LA) in patients with symptomatic severe carotid artery stenosis. Method. We retrospectively collected the data on 64 patients who underwent CEA under GA (47 patients) and LA (17 patients) at our hospital from January 2010 to January 2014. All clinical, demographics, preoperative risk factors and postoperative data were compared for postoperative results. Surgical indications, techniques, and complications were also compared. Result. The groups were similar for age, gender and preoperative risk factors. There were no significant differences in death (GA: 4.2\% vs. LA: 0\%; $\mathrm{p}=1.0$ ), stroke (GA: 4.2\% vs. LA: $0 \% ; \mathrm{p}=1.0$ ), death/ stroke rate (GA: $2.1 \%$ vs. LA: $0 \% ; \mathrm{p}=1.0)$, nerve injury (GA: $2.1 \%$ vs. LA: 5.8\%; $\mathrm{p}=0.464)$, saphenous vein patch closure (GA: $83 \%$ vs. LA: $59 \%$; $\mathrm{p}=0.051)$, shunt rate (GA: $8.5 \%$ vs. LA: $6 \% ; \mathrm{p}=1.0$ ), hospital stay (GA: 8.2 \pm 5.7 day vs. LA: $6.2 \pm 2.9$ day, $\mathrm{p}=0.275)$, hematoma rate (GA: $0 \%$ vs. LA: $5.8 \% ; \mathrm{p}=0.266)$ and transient ischemic attack rate (GA: $4.2 \%$ vs. LA: $0 \% ; \mathrm{p}=1.0)$ between the two techniques. Mortality occurred in two patients (both in the GA group) due to stroke and myocardial infarction. Conclusion. Carotid endarterectomy performed safely under general or local anesthesia is associated with low morbidity and mortality rates. Local anesthesia can be a safe option for evaluating the better neurological status during operation.
\end{abstract}

Eur Res J 2015;1(2):39-43

Keywords: Carotid endarterectomy, general anesthesia, local anesthesia, carotid artery stenosis

\section{Introduction}

Carotid artery disease is one of the most important causes of stroke. In randomized controlled studies showed that rates of death and stroke are reduced by carotid endarterectomy for carotid artery stenosis in patients with symptomatic or asymptomatic [1-3]. Carotid endarterectomy (CEA) can be performed under general anesthesia (GA) or local anesthesia (LA). Succesful outcome can depend on technique which is used. CEA can be performed safely under LA and can improve the results as compared to GA [2].

The aim of this study was to compare the results

Address for correspondence:

Faruk Toktas, MD, Department of Cardiovascular Surgery, Bursa Yuksek Ihtisas Education and Research Hospital, 16330 Bursa, Turkey

Tel:+90(224) 36050 50, Fax: +90(224) 3605055 Email: faruktoktas@gmail.com

Received: 23.03.2015; Accepted: 29.05.2015: Published Online: 04.07.2015 
of CEA performed under GA versus LA and to evaluate the advantages of anesthesia technique on perioperative mortality and morbidity in patients.

\section{Materials and Methods}

\section{Patients}

After local ethics committee approved the study, we retrospectively collected the data on 64 patients who underwent CEA under GA (47 patients) and LA (17 patients) at our hospital from January 2010 to January 2014. Carotid stenosis was diagnosed with history and physical examination followed by Doppler USG, coronary and carotid angiography. Three patients had a history of coronary artery bypass grafting in the GA group.

\section{Anesthesia and Surgical Technique}

All patients were premedicated with midazolam intramuscularly before the operation. In both groups intraoperative monitoring included electrocardiography, invasive blood pressure measured from the contralateral radial artery and pulse oximetry. Induction in general anesthesia was performed with propofol, fentanyl and rocuronium and maintenance of anesthesia was included with isoflurane, fentanyl and rocuronium. Monitoring of neurological function during general anesthesia was based on stump pressure, and selective shunting used if stump pressure was below $50 \mathrm{~mm} \mathrm{Hg}$. Local anesthesia group was administered $2 \%$ lidocaine as local anesthetic. The patients were periodically examined with respect to clinical neurological status, cognitive functions, speech and attention issues, and muscular strength. All patients with altered level of consciousness underwent protective intraluminal shunt placement. Prior to carotid artery clamping, 5000 units of heparin was administered, which was not routinely neutralized. Operations were performed by standard CEA techniques or eversion techniques. At the former, a saphenous vein patch was placed whenever arteriotomy extended to internal carotid artery. In the latter, primary closure was performed.

Neurological deficits were grouped as major or minor. The latter comprised transient ischemic attack or any other events that were terminated within 48 hours. Major neurological deficits included those that persisted more than 7 hours.

\section{Statistical analysis}

Statistical analysis was performed by using SPSS 15.0. All continuous data are expressed as \pm standard error of the mean and categorical data are reported as a percentage. Continuous data were compared by Mann- Whitney-U and paired samples t tests, and non-parametric data by the chi-square test. A p value less than 0.05 was considered statistically significant.

\section{Results}

GA was used in $47(\%$ 73) patients for CEA procedures whereas the LA group included 17 (\% 27) patients who received CEA procedures. Preoperative patient demographics, preoperative risk factors, indications for surgery and comorbidity factors were similar between the two groups and showed in Table 1.

We found no significant differences in the number of patients with preoperative hypertension (GA: $68 \%$ vs. LA: $41 \%$; $\mathrm{p}=0.510)$, coronary artery disease (GA: $62 \%$ vs. LA: $59 \%$; $\mathrm{p}=0.835$ ), chronic obstructive pulmonary disease (GA: 23\% vs. LA: 15\%; $\mathrm{p}=0.463)$, transient ischemic attack (GA: $21 \%$ vs. LA: $29 \%$; $\mathrm{p}=0.517$ ), amarosis fugax (GA: $4 \%$ vs. LA: $6 \%, \mathrm{p}=0.945$ ), cerebrovascular accident (GA: $43 \%$ vs. LA: $29 \%$; $\mathrm{p}=0.341$ ), diabetes (GA: $25 \%$ vs. LA: $12 \%$; $=0.319$ ), smoking (GA: $57 \%$ vs. LA: 59\%; $\mathrm{p}=1.00)$, peripheral occlusive arterial disease (GA: $13 \%$ vs. LA: $24 \%$; $\mathrm{p}=0.295)$ and contralateral ICA lesions, severe stenosis (>70\%) (GA: 89\% vs. LA: $88 \% ; \mathrm{p}=1.00$ ).

Operative variables in the groups are shown in Table 2. There were no statistically significant differences in death (GA: $4.2 \%$ vs. LA: $0 \%$; $=1.00$ ), stroke (GA: $4.2 \%$ vs. LA: 0\%; $p=1.00$ ), death/ stroke rates (GA: $2.1 \%$ vs. LA: $0 \% ; p=1.00)$, nerve injury (GA: $2.1 \%$ vs. LA: $5.8 \%$; $\mathrm{p}=1.00$ ), use of shunt rates (GA: $8.5 \%$ vs. LA: 6\%; $\mathrm{p}=1.00$ ), saphenous vein patch closure (GA: $83 \%$ vs. LA: $59 \%$; $\mathrm{p}=0.051$ ), length of hospital stay (GA: $8.2 \pm 5.7$ days vs. LA: $6.2 \pm 2.9$ days; $p=0.275$ ), hematoma rates (GA: $0 \%$ vs. LA: 5.8\%; $\mathrm{p}=0.266)$ and transient ischemic attack rates (GA: $4.2 \%$ vs. LA: $0 \% ; \mathrm{p}=1.00$ ) between the two techniques. Mortality occurred in two patients due to stroke and myocardial infarction. The both patients were in the GA group. 
Table 1. Patient demographics and preoperative variables

\begin{tabular}{|c|c|c|c|}
\hline & GA Group (n=47) & LA Group $(n=17)$ & $p$ Value \\
\hline Age (years) & $66.6 \pm 8$ & $67.4 \pm 9$ & $0.727 *$ \\
\hline Sex (male/female) & $40(85) / 7(15)$ & $10(67) / 7(33)$ & $1.0 \%$ \\
\hline \multicolumn{4}{|l|}{ Risk factors } \\
\hline Hypertension & $32(68)$ & $7(41)$ & $0.510 \neq$ \\
\hline Diabetes & $12(25)$ & $2(12)$ & $0.319 \neq$ \\
\hline COPD & $7(15)$ & $4(23)$ & $0.463 \ddagger$ \\
\hline PAD & $6(13)$ & $4(24)$ & $0.295 \ddagger$ \\
\hline Smoking & $27(57)$ & $10(59)$ & $1.0 \%$ \\
\hline IHD & $29(62)$ & $10(59)$ & $0.835 \ddagger$ \\
\hline \multicolumn{4}{|l|}{ Symptoms } \\
\hline TIA & $10(21)$ & $5(29)$ & $0.517 \ddagger$ \\
\hline Amaurosis fugax & $2(4)$ & $1(6)$ & $1.0 \ddagger$ \\
\hline CVA & $20(43)$ & $5(29)$ & $0.341 \div$ \\
\hline \multicolumn{4}{|c|}{ Contralateral Stenosis } \\
\hline$(\%)<50$ & $30(64)$ & $11(65)$ & $0.949 \neq$ \\
\hline $50-69$ & $10(20)$ & $5(59)$ & $0.517 \ddagger$ \\
\hline 70-99 & $4(8)$ & $1(6)$ & $1.0 \%$ \\
\hline Occluded & $1(2)$ & $1(6)$ & $0.464 \ddagger$ \\
\hline Operated & $1(3)$ & $0(0)$ & $1.0 \%$ \\
\hline
\end{tabular}

Numbers in parentheses are percentages. $(*=$ Mann-Whitney U-test, $\neq=$ Chi-squared test, $p=$ statistical value. $\mathrm{COPD}=$ chronic obstructive pulmonary disease, $\mathrm{CVA}=$ cerebral vascular accident, $\mathrm{GA}=$ general anesthesia, $\mathrm{IHD}=$ ischaemic heart disease, $\mathrm{LA}=$ local anesthesia, $\mathrm{PAD}=$ peripheral arterial disease, TIA=transient ischemic attack.

Table 2. Operative and postoperative variables

\begin{tabular}{llll}
\hline & GA & LA & P value \\
\hline Death & $2(4.2)$ & $0(0)$ & $1.0 \ddagger$ \\
Stroke & $2(4.2)$ & $0(0)$ & $1.0 \ddagger$ \\
TIA & $2(4.2)$ & $0(0)$ & $1.0 \ddagger$ \\
Myocardial infarction & $1(2.1)$ & $0(0)$ & $1.0 \ddagger$ \\
Nerve injury & $1(2.1)$ & $1(5.8)$ & $0.464 \ddagger$ \\
Shunt rate & $4(8.5)$ & $1(6)$ & $1.0 \ddagger$ \\
Hospital stay (day) & $8.2 \pm 5.7$ & $6.2 \pm 2.9$ & $0.275 \ddagger$ \\
\hline
\end{tabular}

Numbers in parentheses are percentages. $\$=$ Chi-squared test, $\mathrm{p}=$ statistical value. $\mathrm{GA}=$ general anesthesia, LA=local anesthesia, TIA=transient ischemic attack, 


\section{Discussion}

Previous randomized controlled studies and metaanalyses have shown that reduced rates of death or stroke are associated with CEA performed for both symptomatic and asymptomatic carotid artery stenosis [1-4]. European Vascular Surgery guidelines strongly recommend CEA for symptomatic carotid artery stenosis degree greater than $70 \%$. CEA operation is also reasonable when the stenosis degree is greater than $50 \%$ unless the operative rate for stroke or mortality of the performing center exceeds $6 \%$ (North American Symptomatic Carotid Endarterectomy Trial; NASCET) [5]. In our institutional experience, a mortality rate was $4.2 \%(n=2)$. Although many methods including transcranial Doppler USG, stump pressure measurement, peri-operative EEG and somato-sensorial evoked potentials, have been used to establish the level of cerebral perfusion during arterial cross-clamping, there is no consensus to answer whether which technique is superior? Gurer et al. [6] reported that LA was associated with a significantly lower operation time, shunt usage rate, length of hospital stay, and rates of permanent stroke. Restenosis rates, neurological events, and deaths were similar in the 2 groups at long-term follow-up. However, the rate of shunt placement as well as operative time was lower in LA group than the general anesthesia group. Similarly, intensive care unit requirement, duration of hospital stay, and treatment costs were also lower in the local anesthesia group $[7,8]$.

In a study by Surer et al. [9] a greater benefit was observed with use of LA with respect to results of intraoperative motor and mental monitoring. LA also provided more protective effects against complications associated with intubation in elderly patients with comorbid conditions, particularly chronic respiratory diseases. Lutz et al. [3] did not report any significant difference between LA and GA groups with regard to death or stroke, while cerebral events (ischemic attack and stroke) and haematomas were more prevalent in the general anesthesia group. One patient in LA group was reoperated for a haematoma in our study. Halm et al. [10] performed a multivariate analysis for clinical features and operative techniques responsible from risk-adjusted rates of combined death and nonfatal strokes or all strokes. In their study, patients with no carotid symptoms had a death or stroke rate of $2.28 \%$; patients with carotid TIAs had a rate of $2.93 \%$; and those with preoperative stroke had a rate of $7.11 \%$. They found three factors associated with a greater risk-adjusted likelihood of complications: stroke as the indication of surgery, presence of coronary artery disease, and contralateral carotid stenosis. LA usage and patch closure technique application were associated with significant reductions in risk-adjusted odds of death or stroke. The authors suggested that these 2 operative techniques may be associated with reduced death or stroke rates. Stoner et al. [11] reported a significantly reduced perioperative complication rate associated with use of LA, especially in high-risk patients undergoing CEA. On the contrary, some studies found no significant differences between LA and GA in terms of stroke, death, and myocardial infarction at postoperative 30 days [12-15]. Surgical strategies including one- or two-stage operations have been suggested to minimize perioperative neurological and cardiac complications $[16,17]$. In a sequential retrospective study Ferrero et al. [18] compared the results between LA and GA for 428 CEAs. In their study the morbi-mortality was not influenced by the type of anesthesia used for carotid surgery. They did not detect statistical difference in the perioperative neurological and cardiopulmonary complication rates between LA and GA groups. In another retrospective study, Watts et al. [19] reported that there was no difference between LA and GA with regard to neurologic complications with 582 patients. Kasprzak et al. [20] could also not observed significant differences in the perioperative neurological and cardiopulmonary complication rates between LA and GA in patients undergoing CEA. General Anesthesia versus Local Anesthesia for Carotid Surgery (GALA) trial was a multicenter ( 95 centers in 24 countries), randomized controlled study comparing LA and GA during surgery in 3526 patients who had either symptomatic or asymptomatic carotid stenosis. It showed no significant difference between the two study groups at 30-day follow-up with respect to death, stroke, stroke or death, myocardial infarction, and length of hospital stay [2].

\section{The limitation of the study}

Firstly, this study is a retrospective and single center experience. Secondly, the number in the study groups was low, therefore statistical analysis was limited. 
Our clinical experience and results of CEA are consistent with literature. Incidence of stroke and death after both procedures is low. Nonrandomized clinical trials proposed potential benefits of LA over GA, but these studies have a retrospective review. Type of anesthesia does not affect the outcome of surgical treatment of carotid disease. LA can be a safe option for evaluating the better neurological status during operation.

\section{Conflict of interest}

The authors disclosed no conflict of interest during the preparation or publication of this manuscript.

\section{Financing}

The authors disclosed that they did not receive any grant during conduction or writing of this study.

\section{References}

[1] Tangkanakul C, Counsell C, Warlow C. Local versus general anaesthesia for carotid endarterectomy. The Cochrane Database of Systematic Reviews. 2002;2:CD000126.

[2] Lewis SC, Warlow CP, Bodenham AR et al. GALA Trial Collaborative Group. General anaesthesia versus local anaesthesia for carotid surgery (GALA): a multicentre, randomised controlled trial. Lancet. 2008;372(9656):2132-42.

[3] Lutz HJ, Michael R, Gahl B, Savolainen H. Local versus general anaesthesia for carotid endarterectomy-Improving the gold standard? Eur J Vasc Endovasc Surg. 2008;36(2):145-9.

[4] Hidiroglu M, Çetin L, Kunt A, Karakifli O, Küçüker A, Sener E. Early results of carotid endarterectomy for carotid artery diseases. Turk Gogus Kalp Dama. 2010;18(3):190-5.

[5] Liapis CD, Bell PR, Mikhailidis D et al. ESVS guidelines. Invasive treatment for carotid stenosis:indications, techniques. Eur J Vasc Endovasc Surg. 2009;37(4):10-19.

[6] Gurer O, Yapici F, Yapici N, Ozler A, Isik O. Comparison between local and general anesthesia for carotid endarterectomy: early and late results. Vasc Endovasc Surg. 2012;46(2):131-8.

[7] Kalko Y, Kafali E, Aydin U, Kafa U, Kosker T, Basaran M et al. Surgery of the Carotid Artery : Local anaesthesia versus general anaesthesia. Acta Chir Belgica. 2007;107(1):53-7.

[8] McCarthy RJ, Walker R, McAteer P, Budd JS, Horrocks M. Patient and hospital benefits of local anaesthesia for carotid endarterectomy. Eur J Vasc Endovasc Surg. 2001;22(1):13-8.

[9] Surer S, Yay K, Camkiran A, Bekmezci M, Darcin OT. Carotid endarterectomy with Local anaesthesia in patients with advanced age and chronic obstructive pulmonary disease: early term results. Turk J Geriatr. 2013;16(4):372-5.

[10] Halm EA, Hannan EL, Rojas M, Tuhrim S, Riles TS, Rockman $\mathrm{CB}$ et al. Clinical and operative predictors of outcomes of carotid endarterectomy. J Vasc Surg. 2005;42(3):420-8.

[11] Stoner MC, Abbott WM, Wong DR, Hua HT, Lamuraglia GM, Kwolek CJ et al. Defining the high-risk patient for carotid endarterectomy: an analysis of the prospective National Surgical Quality Improvement Program database. J Vasc Surg. 2006;43(2):28595.

[12] Rerkasem K, Rothwell PM. Local versus general anaesthesia for carotid endarterectomy.The Cochrane Database of Systematic Reviews. 2008;4:CD000126. pub3.

[13] Markovic D, Vlajkovic G, Sindjelic R, Markovic D, Ladjevic N, Kalezic N. Cervical plexus block versus general anesthesia in carotid surgery: single center experience. Arch Med Sci. 2012;8(6):1035-40. [14] Sideso E, Walton J, Handa A. General or local anesthesia for carotid endarterectomy the-"real-world" experience. Angiology. 2011;62(8):609-13.

[15] Schechter MA, Shortell CK, Scarborough JE. Regional versus general anesthesia for carotid endarterectomy: the American College of Surgeons National Surgical Quality Improvement Program perspective. Surgery. 2012;152(3):309-14.

[16] Gensare B, AngelisI I, Weingartner J, Neumaier-Prauser P, Spiliopoulos K, Kemkes BM. Simultaneous carotid endarterectomy and cardiac surgery-additional risk factor or safety procedure? J Thorac Cardiovasc Surg. 2003;51(1):22-7.

[17] Yildirim T, Akgün S, Sur H, Kinikoglu H, Bilgin F, Arsan S. Short-term results of simultaneous carotid endarterectomy and myocardial revascularization. Turk Gogus Kalp Dama. 2004;12(3):15660 .

[18] Ferrero E, Ferri M, Viazzo A, Ferrero M, Gaggiano A, Berardi G, Pecchio A, Piazza S,Cumbo P, Nessi F. Carotid endarterectomy: Comparison between general and local anesthesia. Revision of our experience with 428 consecutive cases. Ann Vasc Surg. 2010;24(8):10347.

[19] Watts K, Lin PH , Awad S, McCoy S, Felkai D, Zhou W et al. The impact of anaesthetic modality on the outcome of carotid endarterectomy. Am J Surg. 2004;188(6):741-7.

[20] Kasprzak PM, Altmeppen J, Angerer M, Mann S, Mackh J, Topel I. General versus locoregional anaesthesia in carotid surgery: a prospective randomised trial. Vasa. 2006;35(4):232-8. 